\title{
Use of a Scanning Electron Microscope for the Examination of Actinomycetes
}

\author{
By S. T. WILLIAMS AND F. L. DAVIES \\ Hartley Botanical Laboratories, University of Liverpool, Liverpool 3
}

(Accepted for publication 28 February 1967)

SUMMARY

Organisms belonging to several genera of the order Actinomycetales were examined using the 'Stereoscan' electron microscope of the Cambridge Instrument Company. Unlike the transmission electron microscope, this instrument provides surface views of fine structures without the need for preparation of replicas. Using a simple preparation procedure, surface views of intact sporing structures of several actinomycetes were observed over a range of magnifications. The potential value of using scanning electron microscopes for the examination of actinomycetes was assessed.

\section{INTRODUCTION}

Investigations of the structure of organisms belonging to various genera of the Actinomycetales with transmission electron microscopes have provided much useful information. Details of the internal structure of vegetative and reproductive structures of several genera have been obtained from the examination of ultra-thin sections. Details of the development of spores in sporangia-forming genera have been given by Rancourt \& Lechevalier (1963) who studied Microellobospora, Lechevalier \& Holbert (1965) who examined Actinoplanes, and Lechevalier, Lechevalier \& Holbert (1966) who examined Streptosporangium, Spirillospora and Actinoplanes.

The fine structure of reproductive and vegetative organs of the genus Streptomyces has been investigated by many workers (Moore \& Chapman, 1959; Stuart, 1959; Glauert \& Hopwood, 1960; Chen, 1964; Painter \& Bradley 1965). Rancourt \& Lechevalier (1964) were able to outline the developmental sequence of spores of Streptomyces viridochromogenes and $S$. violaceus by the examination of sections. Studies of other genera include those of Overman \& Pine (1963) on Actinomyces species and Kawato \& Inoue (1965) on Nocardia asteroides.

Examination of actinomycetes with the transmission electron microscope has also provided taxonomic criteria. Observation of the silhouettes of whole spores of various species of the genus Streptomyces provides details of their surface ornamentation and this has been shown to be a useful taxonomic character (Küster, 1953; Preobrazhenskaya et al. 1960; Tresner, Davies \& Backus, 1961).

Surface views of electron-dense structures, such as actinomycete spores, have until recently been obtainable only by the examination of carbon replicas of the structures. Replication techniques have had only limited application in studies of actinomycetes. Hopwood \& Glauert (1961) examined carbon replicas of spores of Streptomyces violaceoruber and, using similar techniques, other species of this genus were examined by Dietz \& Matthews (1962) and Preobrazhenskaya et al. (1965). 
We have examined organisms belonging to several actinomycete genera, using the 'Stereoscan' electron microscope developed by the Cambridge Instrument Company. This is a scanning electron microscope which has a larger depth of focus even than the transmission type, providing a surface view of whole structures. The procedures used for the examination of actinomycetes are described, and from the results obtained the potential value of such an instrument for studies of this group of micro-organisms is assessed.

\section{METHODS}

Strains used. These were as follows: Actinoplanes sp., Microbispora rosea (RIA 477), Microellobosporia flavea (IMRU3858), Micromonospora sp., Nocardia rubra (CBS), Streptomyces finlayi (ISP 5218), S. viridosporus (ISP 5243), Streptomyces sp., Streptosporangium sp., and Thermoactinomyces vulgaris (Küster P121). (RIA, U.S.S.R. Research Institute for Antibiotics, Moscow; IMRU, Institute of Microbiology, Rutgers, New Brunswick, U.S.A.; CBS, Centraalbureau voor Schimmelcultures, Baarn, Netherlands; ISP, Code number of culture in International Streptomyces Project; Prof. E. Küster, Dept. of Industrial Microbiology, Dublin, Eire.)

Media. With the exception of Nocardia rubra and Thermoactinomyces vulgaris, which were grown on Oxoid Nutrient Agar, all strains were grown on oatmeal agar (Waksman, 1961).

Culture Method. After preliminary tests, the following procedure was found to be satisfactory for providing a growth of actinomycetes which could be examined, with the minimum of disturbance, in the scanning electron microscope. Circular glass coverslips, $\frac{1}{2}$ in. in diameter, were sterilized by autoclaving. Each of these was then inserted at an angle of about $45^{\circ}$ into solidified medium in a Petri dish until about half the coverslip was in the medium. An inoculum of actinomycetes from slope cultures was then spread along the line where the upper surface of the coverslip met the medium, using a fine wire needle. The plates were then incubated, the length of incubation period needed for each strain to produce mature sporing structures having been previously determined. All were incubated at $25^{\circ}$ except for Thermoactinomyces vulgaris which was grown at $45^{\circ}$. After incubation the actinomycetes were growing both on the medium and in a line across the upper surface of the coverslips. This line of growth remained attached to the coverslips when they were carefully withdrawn from the medium. A similar culture method for actinomycetes was described by Kawato \& Shinobu (1959).

Preparation of cover-slip cultures for examination. With the actinomycetes uppermost the coverslips were attached by 'Durofix' adhesive, to solid metal specimen stubs which had a circular face of the same diameter as the coverslips. The upper surface of each coverslip was then coated, under vacuum, with a film, about $500 \AA$ thick, of gold-palladium alloy. This process was completed in $15 \mathrm{~min}$. and four preparations were coated at a time. During examination in the scanning electron microscope, the film allowed excess charge built up on the specimens to leak away, but was not thick enough to decrease the resolution. The coverslips were coated within $10 \mathrm{~min}$. of their removal from the medium and thus the actinomycetes were alive until they were placed under vacuum and distortions from slow air drying were minimized. Once coated with gold-palladium, the specimens were ready for examination in the microscope. 
Examination with the scanning electron microscope. The metal stubs with their attached coated coverslips were placed in the specimen chamber of the microscope. The field was scanned at low magnification until the line of growth was detected. Areas with clear, intact sporing structures were then selected for examination at higher magnification. Suitable subjects were photographed using Ilford H.P. 3 film.

In this instrument the specimen is scanned by a beam of electrons and these generate secondary electrons by the ionization of atoms of the specimen. Some of these have sufficient energy to escape into the vacuum and are collected, together with some reflected primary electrons, to give the screen image. The 'shadowed' appearance of the specimen, which emphasizes surface details, is due to the positioning of the collector for the secondary electrons at an angle to the original beam.

\section{RESULTS}

The results obtained are shown in Plates 1-4. It can be seen that the images produced by the scanning electron microscope were similar to those seen with a binocular light microscope but at greater magnification. The instrument can be used over a wide range of magnification but for actinomycetes the most useful range is from 1000 to 30,000 times. Thus in Pl. 1, figs. 1-3, views of the same streptomyces species are shown at three different magnifications. At lower magnifications the general morphology of the intact spore chains is well illustrated, while the smooth indented surface of the spores can be seen at higher magnifications.

Examination of Streptomyces species. Three species of Streptomyces were examined. It was known from previous examinations with a transmission electron microscope that they had variously ornamented spore surfaces. Streptomyces viridosporus had spores with spines, those of S. finlayi had hairs and those of another Streptomyces sp. were smooth. As previously stated, the ornamentation of spore surfaces is an important taxonomic character for species of the genus Streptomyces. It is considered to be one of the more stable attributes of streptomycetes and was included in the criteria used in the International Streptomyces Project for the redescription of type cultures (Shirling \& Gottlieb, 1966). The ornamentation of the spores of S. viridosporus and $S$. finlayi was clearly revealed here (Pl. 1, fig. 4; PI. 2, fig. 5). Whole surface views of ornamented Streptomyces spores were obtained by Preobrazhenskaya et al. (1965) from examination of carbon replicas. They obtained replicas of smooth spores and of spores with wart-like projections and spines, but no example of a carbon replica of a spore with hairs was shown. To obtain carbon replicas of such delicate and flexible structures would be extremely difficult.

Using the scanning electron microscope it was also possible to examine intact chains of spores, and observations of those of $S$. viridosporus revealed some interesting features. Some chains were composed of spores all of which had spiny surfaces (P1. 2, fig. 5); in others both smooth and spiny spores occurred (Pl. 2, fig. 7), while in some the chains were composed entirely of spores with smooth surfaces (P1. 2, fig. 6). Similar findings were made by Baldacci, Balduzzi \& Amici (1957) and Hodgkiss \& Mitchell (1965) from their examinations of silhouettes of spores with the transmission electron microscope. Baldacci et al. (1957) suggested that this variation in appearance was because some of the spores had lost their outer coat on which the spines were located. This suggestion agrees with the details of spore development in 
S. viridochromogenes given by Rancourt \& Lechevalier (1964). They showed that the spines were on a superficial layer which did not adhere strongly to the surface of mature spores. We obtained no additional evidence on the cause of this phenomenon and further study is needed. When ornamentation of spores is used as a taxonomic character it is important to take account of this variation and examine a wide range of spore chains. This can be easily done using the scanning electron microscope at relatively low magnifications (P1. 1, fig. 2), when details of the overall spore-chain morphology, another important taxonomic character, can also be observed.

In P1. 2, fig. 6 it can be seen that the smooth spores of Streptomyces viridosporus had lateral depressions; these are also evident in the smooth spores of Streptomyces sp. (P1. 1, fig. 3). Recently, Tresner, Davies \& Englert (1966) noted that the smooth spores of some streptomycetes had a 'phalange' shape in outline and in section; it seems likely that these workers observed spores with similar depressions to those shown here. Care must be taken when interpreting such structures in the electron microscope, as the depressions may be artifacts caused by the partial collapse of spore walls under vacuum.

Examination of sporangia-forming genera. Examples of three genera forming sporangia were examined: Actinoplanes sp., Streptosporangium sp. and Microellobosporia flavea. The internal structure of sporangia of Actinoplanes was studied by Lechevalier \& Holbert (1965). From their examination of ultra-thin sections they suggested that spores in a mature sporangium gave it a bulging appearance; this was confirmed in this study (Pl. 2, fig. 8). Sections of sporangia of Streptosporangium examined by Lechevalier et al. (1966) indicated that the outer sporangial envelope was a loosely wrinkled structure and this was also evident from the observations of intact sporangia with the scanning electron microscope (Pl. 3, fig. 9). Sections of Microellobosporia were examined by Rancourt \& Lechevalier (1963) who also noted that the sporangial wall had a wrinkled membranous form. This was true of the mature three-spored sporangium observed here (Pl. 3, fig. 11). In younger sporangia the wall was more regular (Pl. 3, fig. 10), possibly because it was still attached to tissues inside the sporangium.

Examination of other genera. The spores of the thermophilic actinomycete, Thermoactinomyces vulgaris, had a polygonal shape when viewed with the scanning electron microscope (P1. 3, fig. 12). Other workers, examining silhouettes of spores of thermophilic actinomycetes with the electron microscope, have noted their angled outline. Agre (1962) observed 8- to 10-sided spore silhouettes in a thermophilic Micromonospora vulgaris and Kudrina \& Maksimova (1963) noted similar spores in a thermophilic $M$. thermolutea. As both of these actinomycetes formed their spores on aerial mycelium above the medium, they would not be included in the genus Micromonospora by some workers, but placed in Thermoactinomyces. Thus it is possible that the shape of Thermoactinomyces spores may be a useful diagnostic character for this genus.

Some of the stages in the development of the paired spores of Microbispora rosea were evident in $\mathrm{Pl}$. 4, fig. 13. Younger spores were rather elongated, without any external indication of a paired structure. Gradually they became broader and the central constriction became more marked until a typical paired spore was formed. This pattern of development is similar to the one indicated by the drawings of Nonomura \& Ohara (1957).

In the micrographs of Nocardia rubra (P1. 4, figs. 14, 15) can be seen its hyphae at 
various stages of fragmentation. The Micromonospora species studied produced spores which were mainly sessile, arising directly from the hyphae without a sporophore. Two sessile spores at different stages of development are shown in Pl. 4, fig. 16.

\section{DISCUSSION}

The value of the scanning electron microscope for the examination of actinomycetes

Using this instrument, surface views of reproductive and vegetative structures at high magnification were obtained. The method of preparing specimens for observation was simple and rapid, up to 12 could be prepared in an hour. In addition, intact sporing structures could be examined. The only other way of obtaining surface views of these electron-dense structures at high magnification is by examination of carbon replicas with a transmission electron microscope. While the resolving power of such instruments is higher than that of the scanning type, about $5 \AA$ as opposed to about $500 \AA$, the preparation of carbon replicas is a laborious procedure needing great care. Also it is impossible to obtain replicas of certain types of surface and the technique can seldom provide views of intact sporing structures. Therefore, for most purposes, a scanning electron microscope would be more useful.

Using this instrument at relatively low magnifications (1000-6000), general morphological details of intact sporing structures were easily observed. Normally such features, which are important in the taxonomy of these organisms, are observed with the light microscope. However, the small size of actinomycetes requires the light microscope to be used near the limit of its resolving power and the application of stains and immersion oil to preparations often results in the disruption of important structures. The scanning electron microscope provided views similar to those seen when intact specimens are examined with the lower-power objectives of the light microscope but at considerably higher magnification.

From this preliminary study, several possible applications of the scanning electron microscope to studies of actinomycetes can be suggested. As the preparation procedure is so simple and rapid, this type of instrument could be most useful for the routine examination and identification of specimens. This can be achieved more quickly and more accurately than when a light microscope is used, and at the same time features hitherto seen only with the transmission electron microscope (e.g. ornamentation of spore surfaces) are visible.

In studies of developmental processes, the scanning electron microscope would be a useful tool, especially if used to supplement information obtained from the examination of thin sections with the transmission microscope. Other applications which can be envisaged include investigations of the distribution and growth of actinomycetes in their natural habitats, such as the soil, and study of the occurrence of hyphal fusions in genetical studies.

The authors wish to express their gratitude to the Cambridge Instrument Company for permitting the use of their 'Stereoscan' microscope. The kind assistance of Miss P. J. Killingworth, Miss C. E. Moss and Mr K. W. Trevatt is gratefully acknowledged. 


\section{REFERENCES}

AGRE, N. S. (1962). Electron microscopic investigations of spores of Micromonospora vulgaris. Mikrobiologiya 31, 77.

Baldacci, E., Balduzzi, P. \& AMICI, A. M. (1957). Observations of some Actinomyces isolated from soil samples from Israel, and their morphology under electronic microscopy. Bull. Res. Coun. Israel 5, 263.

ChEN, P. L. (1964). The membrane system of Streptomyces cinnamonensis. Am. J. Bot. 51, 125.

DIETZ, A. \& MATHEwS, J. (1962). Taxonomy by carbon replication. I. An examination of Streptomyces hygroscopicus. Appl. Microbiol. 10, 258.

GlauerT, A. M. \& Hopwood, D. A. (1960). The fine structure of Streptomyces coelicolor. I. The cytoplasmic membrane system. J. biophys. biochem. Cytol. 7, 479.

HodGKISS, W. \& MrTCHELL, T. G. (1965). Variation in spore morphology in a streptomycete. J. gen. Microbiol. 41, xix.

Hopwood, D. A. \& GLAUERT, A. M. (1961). Electron microscope observations on the surface structures of Streptomyces violaceoruber. J. gen. Microbiol. 26, 325.

KAWATA, T. \& INOUE, T. (1965). Ultrastructure of Nocardia asteroides as revealed by electron microscopy. Jap. J. Microbiol. 9, 101.

Kawato, M. \& Shinobu, R. (1959). On Streptomyces herbaricolor nov.sp. Supplement: A simple technique for the microscopical observation. Mem. Osaka Univ. lib. Arts Educ. 8, 114.

KudRINA, E. S. \& MAKsimova, T. S. (1963). Some species of thermophil Actinomyces from soils of China and their antibiotic properties. Mikrobiologiya 32, 623.

KüSTER, E. (1953). Beitrag zur Genese und Morphologie der Streptomyceten-sporen. VIth Int. Congr. Microbiol. (Rome), p. 114.

LeChevalier, H. \& Holbert, P. E. (1965). Electron microscopic observation of the sporangial structure of a strain of Actinoplanes. J. Bact. 89, 217.

LeCheVAlier, H. A., LeChevalier, M. P. \& HolberT, P. E. (1966). Electron microscopic observation of the sporangial structure of strains of Actinoplanaceae. J. Bact. 92, 1228.

MOORE, R. T. \& ChAPMAN, G. B. (1959). Observations of the fine structure and modes of growth of a streptomycete. J. Bact. 78, 878.

Nonomura, H. \& OHARA, Y. (1957). Distribution of actinomycetes in the soil. II. Microbispora, a new genus of Streptomycetaceae. J. Ferment. Technol. Osaka. 35, 307.

OVERman, J. R. \& PINE, L. (1963). Electron microscopy of cytoplasmic structures in facultative and anaerobic Actinomyces. J. Bact. 86, 656.

PaINTER, B. G. \& BRADLEY, S. G. (1965). Observation on the structure of Streptomyces venezuelae. Bact. Proc. p. 5.

Preobrazhenskaya, T. P., Maksimova, T. S., Lukivanovich, V. M. \& Evko, E. I. (1965). Application of the carbon replica method to the electron microscopic study of the surface of actinomycete spores. Mikrobiologiya 34, 519.

Preobrazhenskaya, T. P., Kudrina, E. S., Maksimova, T. S., Sveshnikova, M. A. \& Boyarskaya, R. V. (1960). Electron microscopy of spores of various actinomycete species. Mikrobiologiya 29, 51.

RANCOURT, M. \& LECHEVALIER, H. A. (1963). Electron microscopic observations of the sporangial structure of an actinomycete, Microellobosporia flavea. J. gen. Microbiol. 31, 495.

RANCOURT, M. \& LeCHEVALIER, H. A. (1964). Electron microscopic study of the formation of spiny conidia of Streptomyces. Can. J. Microbiol. 10, 311.

ShiRLING, E. B. \& GotTLIEB, D. (1966). Methods for characterization of Streptomyces species. Int. J. Syst. Bact. 16, 313.

StUART, D. C. (1959). Fine structure of the nucleoid and internal membrane systems of Streptomyces. J. Bact. 78, 272.

TRESNER, H. D., Davies, M. C. \& Backus, E. J. (1961). Electron microscopy of Streptomyces spore morphology and its role in species differentiation. J. Bact. 81, 70.

Tresner, H. D., Davies, M. C. \& EnGleRT, M. E. (1966). Morphological subtype of the smoothspored streptomycetes. J. Bact. 91, 1998.

WaKsman, S. A. (1961). The Actinomycetes, vol. 2. Classification, Identification and Description of Genera and Species. Baltimore: The Williams and Wilkins Co. 
Journal of General Microbiology, Vol. 48, No. 2

Plate 1
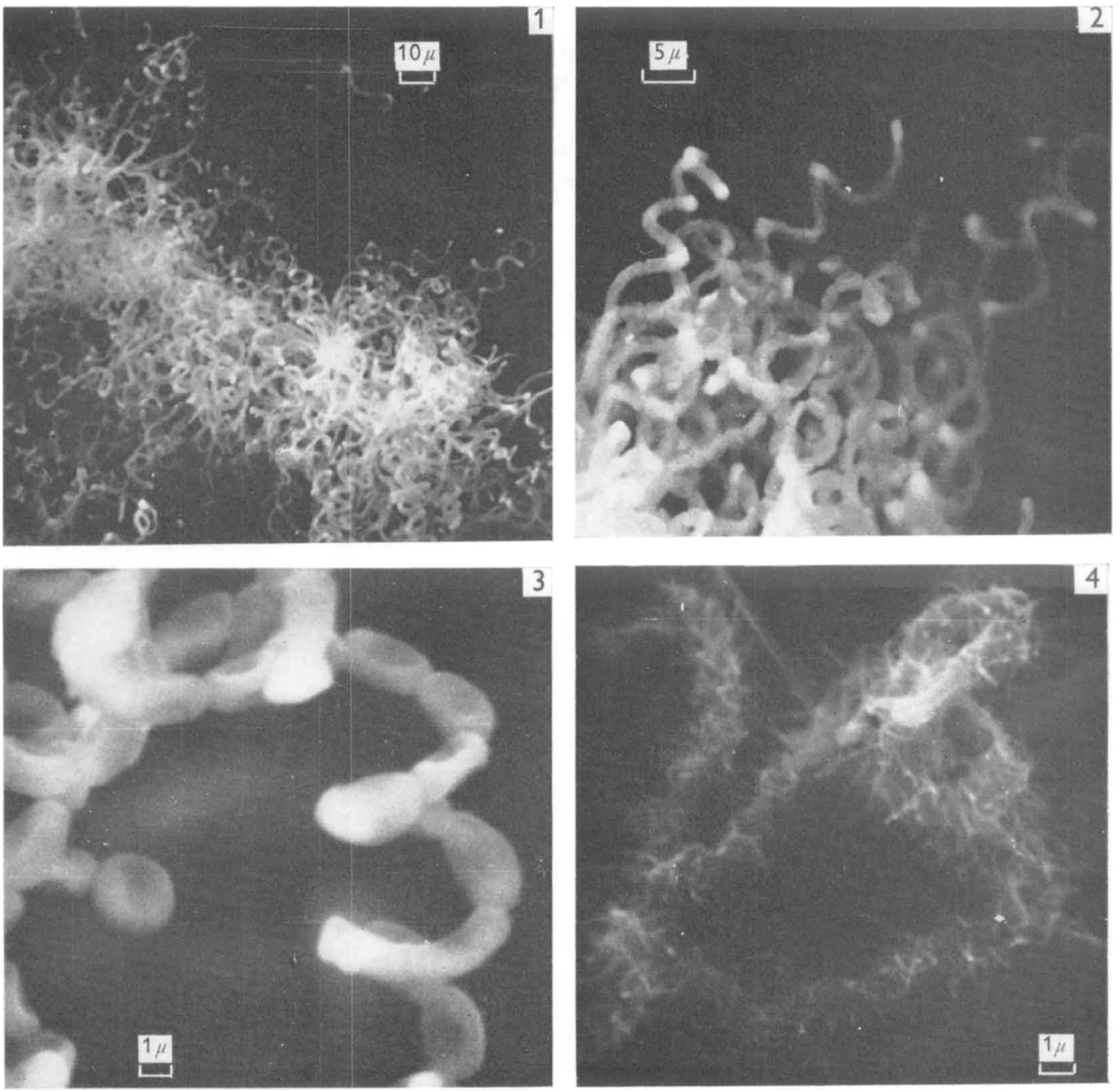

S. T. WILLIAMS AND F. L. DAVIES 
Journal of General Microbiology, Vol. 48, No. 2

Plate 2
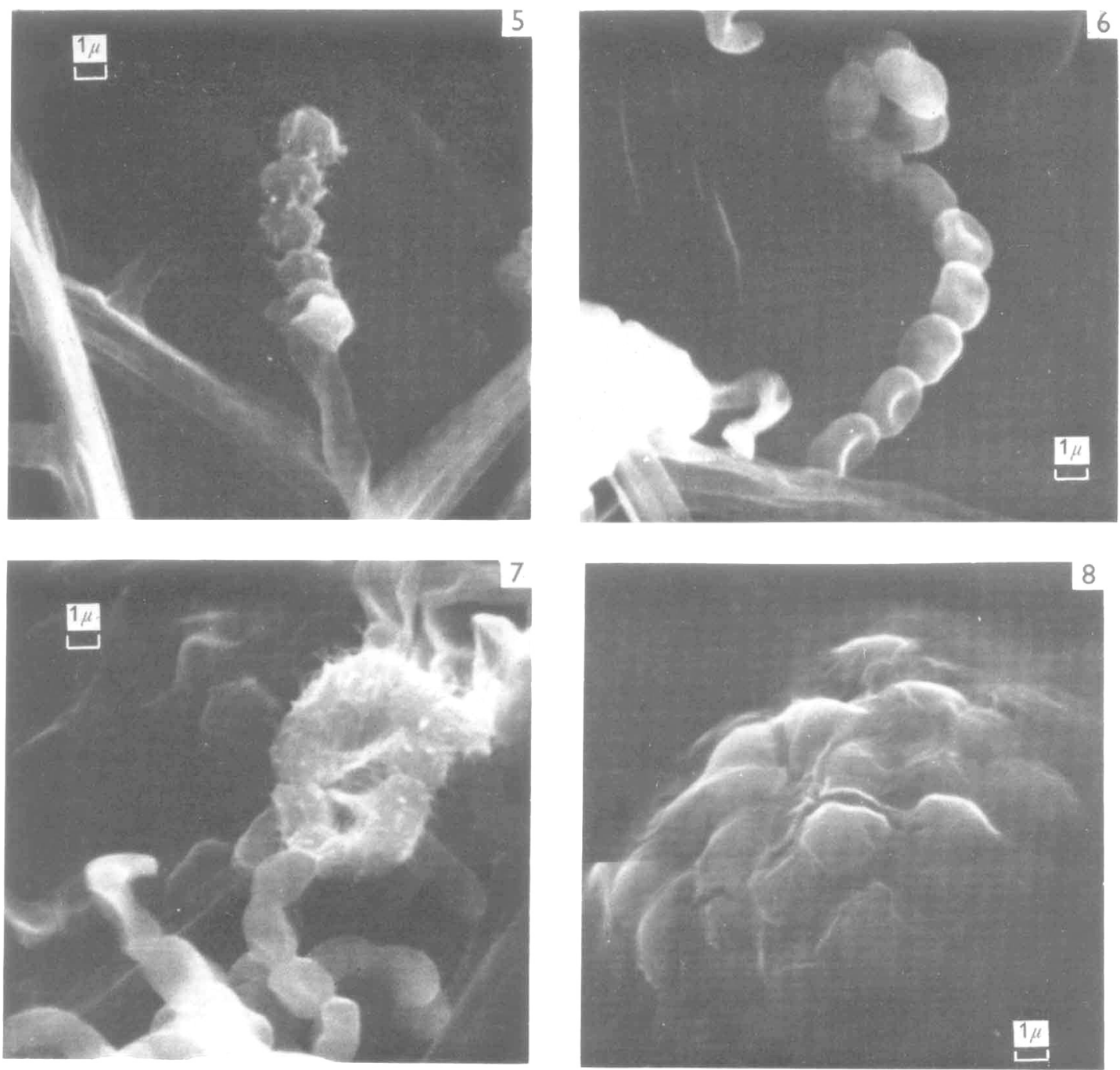

S. T. WILLIAMS AND F. L. DAVIES 
Journal of General Microbiology, Vol. 48, No. 2

Plate 3
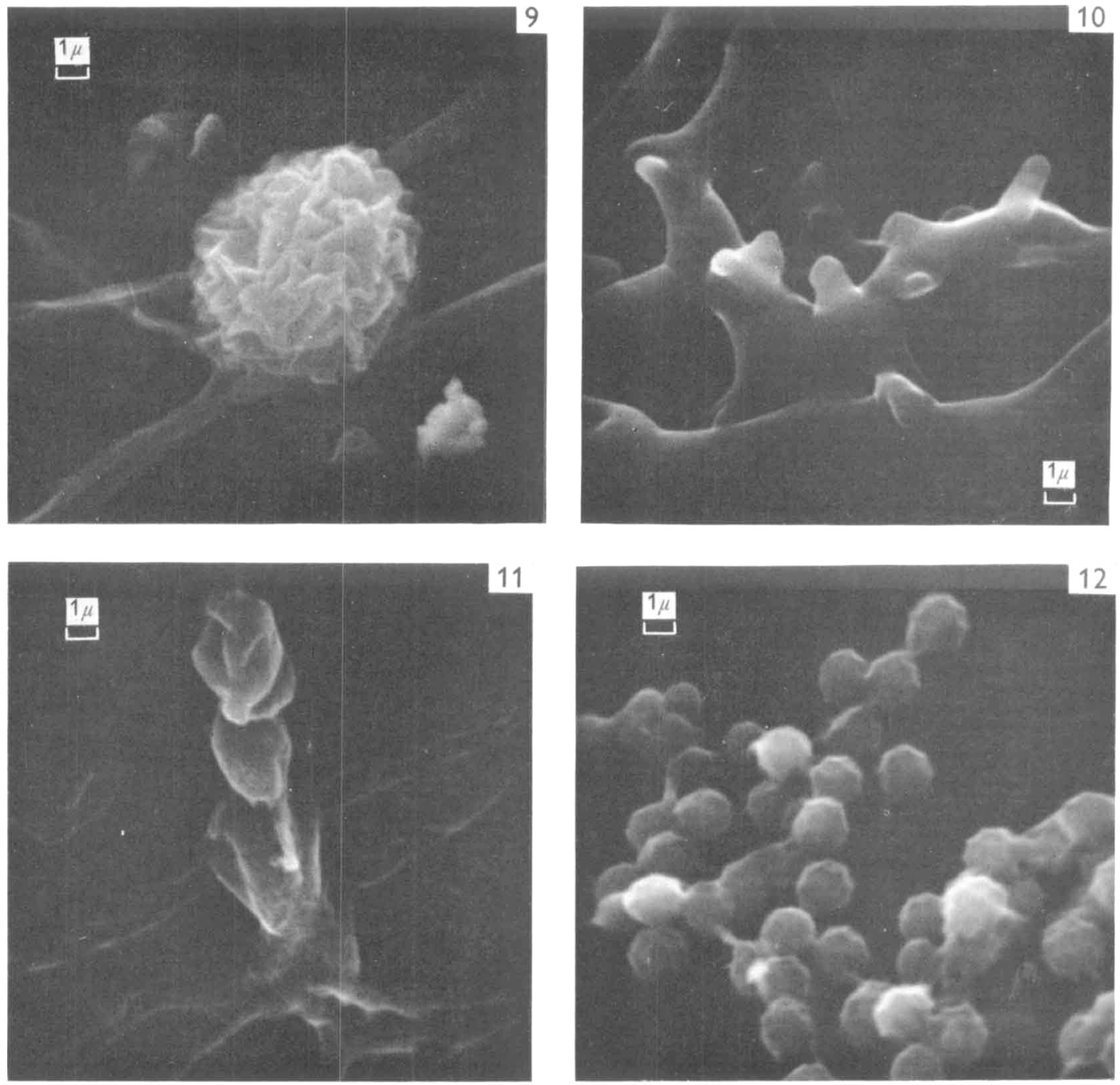

S. T. WILliAMS AND F. L. DAVIES 
Journal of General Microbiology, Vol. 48, No. 2

Plate 4
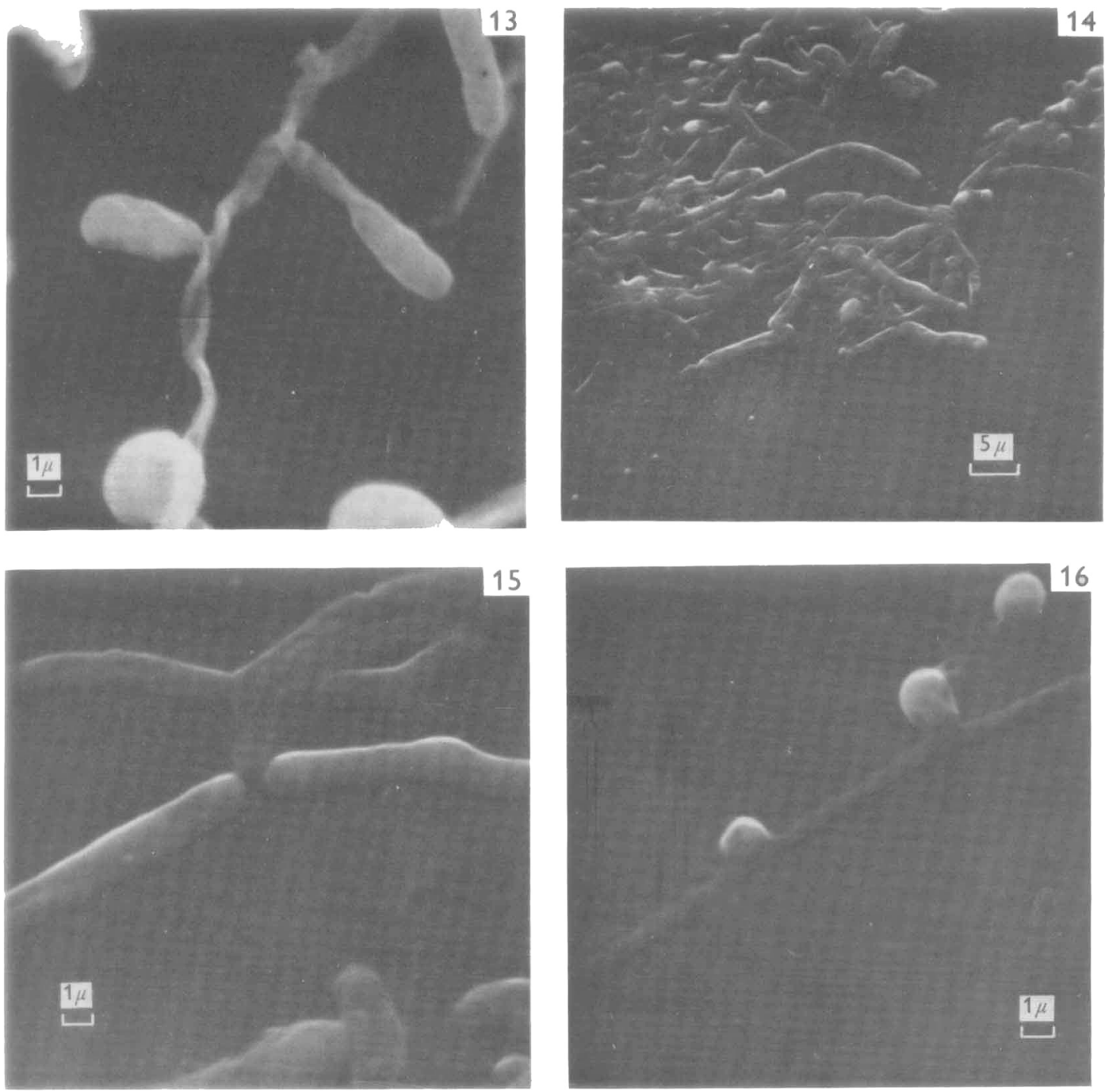

S. T. WILLIAMS AND F. L. DAVIES 


\section{EXPLANATION OF PLATES}

Plate 1

Fig. 1. Streptomyces sp., spiral spore chains. $\times 700$.

Fig. 2. Streptomyces sp., spiral spore chains. $\times 2100$.

Fig. 3. Streptomyces sp., spiral spore chain. $\times 7250$.

Fig. 4. Streptomyces finlayi, chains of hairy spores. $\times 7000$.

\section{Plate 2}

Fig. 5. Streptomyces viridosporus, chain of spiny spores. $\times 6500$.

Fig. 6. S. viridosporus, chain of smooth spores. $\times 6500$.

Fig. 7. S. viridosporus, chain with smooth and spiny spores. $\times 6500$.

Fig. 8. Actinoplanes sp., surface of sporangium. $\times 6750$.

\section{Plate 3}

Fig. 9. Streptosporangium sp., sporangium on sporangiophore. $\times 6250$.

Fig. 10. Microellobosporia flavea, developing sporangia. $\times 6250$.

Fig. 11. M. flavea, mature sporangium. $\times 7000$.

Fig. 12. Thermoactinomyces vulgaris spores. $\times 7000$.

Plate 4

Fig. 13. Microbispora rosea, spores at various stages of development. $\times 6250$.

Fig. 14. Nocardia rubra, fragmenting hyphae. $\times 1800$.

Fig. 15. N. rubra, fragmenting hyphae. $\times 6250$.

Fig. 16. Micromonospora sp., sessile spores. $\times 6250$. 